Çukurova Üniversitesi Mühendislik Mimarlık Fakültesi Dergisi, 29(1), 89-97 ss., Haziran 2014

Çukurova University Journal of the Faculty of Engineering and Architecture, 29(1), pp. 89-97, June 2014

\title{
İpliği Boyalı Pamuklu Kumaşlarda Kumaş Konstrüksiyonunun Boncuklanma ve Aşınmaya Etkisinin Araştırılması
}

\author{
Füsun DOBA KADEM ${ }^{1 *}$, R. Tuğrul OĞULATA \\ ${ }^{1}$ C..̈̈., Mühendislik-Mimarlık Fakültesi, Tekstil Mühendisliği Bölümü, Adana
}

\section{Özet}

Bu çalışma için üç farklı iplik numarası ve üç farklı örgüde, ipliği boyalı pamuklu dokuma kumaşlar üretilmiş, daha sonra bu kumaşların ön terbiyesi yapılmıştır. Kumaşların ilgili standartlara göre, fiziksel özellikleri ile boncuklanma ve aşınma ile kütle kaybı performans özellikleri tespit edilmiştir. Elde edilen sonuçlar değerlendirilerek kumaş konstrüksiyonunun boncuklanma ve aşınma ile kütle kaybına etkisi analiz edilmiştir.

Anahtar Kelimeler: Pamuklu dokuma kumaş, Ön terbiye, Boncuklanma, Aşınma

\section{Investigation of the Fabric Construction of the Effect on Pilling and Abrasion in Yarn Dyed Cotton Fabrics}

\begin{abstract}
For this study, yarn dyed cotton woven fabrics were produced in three different yarn counts and three different patterns, then pre-treatment processes were applied to these fabrics. The physical properties and pilling and mass losses with abrasion performance properties of these fabrics were determined experimentaly according to relevant standarts. The obtained results were evaluated and fabric construction of the effect on pilling and abrasion was analyzed.
\end{abstract}

Key words: Cotton woven fabric, Pre-treatment, Pilling, Abrasion

\footnotetext{
Yazışmaların yapılacağı yazar: Füsun DOBA KADEM, C..̈̈. Mühendislik Mimarlık Fakültesi, Tekstil Mühendisliği Bölümü, Adana.efsun72@cu.edu.tr
} 


\section{GíRiş}

Çalışma kapsamında, \%100 pamuklu hammaddeden, farklı sıklıklardaki atkı ve çözgü ipliklerinden farklı örgülerde dokunmuş kumaşların iplik numarası, atkı ve çözgü sıklıkları, örgü türü gibi fiziksel özellikleri ile boncuklanma ve aşınma ile kütle kaybı performans özellikleri ilgili standartlara göre tespit edilmiştir. Elde edilen sonuçlar değerlendirilerek farklı kumaş konstrüksiyonunun boncuklanmaya ve aşınma ile kütle kaybına etkisi yorumlanmıştır.

Bilindiği gibi boncuklanma, kumaş yüzeyindeki liflerin 'takılarak ayrılması' ve diğer kullanımları sırasında bu liflerin karışması sonucu oluşmaktadır. $\mathrm{Bu}$ tür yüzey bozulması genellikle istenmeyen bir durumdur. Ancak verilen bir boncuklanma seviyesi için tüketici toleransının derecesi giysinin tipine ve kumaşın son kullanımdaki durumuna bağlıdır. Oluşan boncuklanmanın seviyesi genellikle aşağıda verilen birbirine paralel işlemlerin hızı ile tayin edilmektedir.

\section{$\checkmark$ Boncuklanma oluşumuna sebep olan lif dolaşması \\ $\checkmark$ Fazla yüzey lif oluşumu \\ $\checkmark$ Zamanla gelişen lif ve boncuk azalması}

$\mathrm{Bu}$ ișlemlerin hızı life, ipliğe ve kumaş özelliklerine bağlı olup zayıf lif içeren kumaşlardan ziyade sağlam lif içeren kumaşlarda ortaya çıkmaktadır [1].

Martindale metodu ile kumaşların aşınma ile kütle kaybı ise, belirli bir yük altındaki dairesel bir deney parçasının standart kumaşı ile aşındırılması ve deney parçalarının aşınma neticesi kütle kaybının tayin edilmesi esasına dayanmaktadır [1]. Boncuklanma ve aşınma ile kütle kaybı üzerine yapılmış olan literatür çalışmalarından bir kısmı aşağıda özetlenmiştir.

Mohamed ve diğerleri, open-end ve ring eğirme sisteminden elde edilen ipliklerle dokunmuş kumaşların fiziksel özelliklerinin karşılaştırılması ile ilgili bir araştırma yapmışlardır [2]. Yazarlar hem ring hem de open-end iplikli kumaşlarda; kumaş dokusu gevşedikçe, boncuklama performansının düştüğünü yırtılma performansının arttığını ortaya koymuşlardır. Ukponmwan, \%100 pamuklu dokunmuş kumaşların fiziksel ve mekanik özelliklerini (kütle, kalınlık, hava geçirgenlik, sıkıştırma gibi) aşındırma test cihazı kullanıldığında sürtünmeli aşınma nedeniyle ortaya çıkan hasarın etkisi olarak incelemiştir [3]. $\mathrm{Bu}$ çalışma ile kumaş özelliklerinde ortaya çıkan değişikliklerin artımlı aşınmanın bir sonucu olduğu ve aşınma zamanının artışı ile kalınlık, hava geçirgenliği ve sıkıştırma, sürekli olmayan artışlar gösterirken gramaj ve eğilme direncinin sürekli bir azalış gösterdiği tespit edilmiştir. Ukponmwan, pamuk ve pamuk/PES dokuma kumaşlarda ıslak aşınmanın gerilme özelliklerine etkisini incelediği başka bir çalışmasında, Instron Mukavemet Cihazı ile kumaşların kopma yükü ve kopma uzamasını belirlemiş, aşınma öncesi ve sonrası gerilme özellikleri ve gerilme özellikleri üzerine aşınmanın deformasyon etkisini tespit etmiştir [4]. Çalışmada kumaşların aşınma öncesi gerilme özellikleri, kütle, kalınlık, yoğunluk, özgül hacim arasındaki ilişki sunulmuş, ıslak ve nemli aşınmanın her ikisinde de kopma yükü, kopma uzaması ve kopma genleşmesi arasında anlamlı pozitif korelasyon (\%5 ve \%1 düzeyinde) elde edilmiştir. Uygulanan çift taraflı t-testi ile aşınmış ve aşınmamış kumaşlar (1slak ve nemli) arasında anlamlı bir fark olmadığı görülmüştür [4]. Efimova ve diğerleri [5], pamuk/PES, pamuk/viskoz rayon gibi farklı elyaf kompozisyonlarında dokunmuş kumaşların aşınma deneyi üzerine incelemede bulunmuşlardır. Aşınma deneyi için elbise, gömlek, takım elbise, palto gibi farklı kullanım alanı olan kumaşlar bezayağı, dimi gibi farklı örgülerde incelenmiştir. Can iplik özelliklerinin pamuklu bezayağ1 kumaşların bazı mekanik özelliklerine etkileri üzerine bir araştırma yapmış, \%100 pamuklu bezayağı örgü yapısındaki kumaşların kopma, yırtılma ve aşınma mukavemeti üzerinde etkili olan iplik özelliklerini belirlemiştir [6]. Lam ve Postle, yün ve pamuklu kumaşlarda mekanik özelliklerin tespit edilmesi üzerine bir çalışma hazırlamışlar, pamuklu denim kumaşların mekanik ve yüzey özelliklerinin çok değişkenli istatistiksel analiz teknikleriyle incelemesini yapmışlardır [7]. Taşkın ve diğerleri [8], iki farklı numara ve iki 
farklı bükümde \%100 pamuklu kompakt ve konvansiyonel ring iplikleri kullanılarak bezayağı, dimi ve saten dokuma kumaş üretimini gerçekleştirmişlerdir. Çalışmalarında yakma, merserizasyon, pigment baskı, reaktif baskı ve reaktif boyama gibi farklı terbiye işlemlerinin, kompakt ve konvansiyonel ring ipliklerinden dokunmuş kumaşların boncuklanma eğilimi üzerine etkisini incelemişlerdir. Kaynak ve Topalbekiroğlu [9], \% 100 pamuk, Ne 30/1 penye ring ipliğinden 7 farklı doku tipine sahip kumaşların aşınma ve boncuklanma dayanımlarının tespit edilmesi amaciyla Martindale aşınma ve boncuklanma cihazı ile deneyler uygulayarak elde edilen sonuçları değerlendirmişlerdir. Boncuklanma dayanımı, cihazın 2000 devri sonucunda gözlemlenen ortalama boncuk sayısı ile, aşınma dayanımı ise cihazın 15000 devri sonucunda numunelerin ortalama ağırlık kaybının ilk ağırlıklarına oranının yüzdesi olarak ifade edilmiştir. Testler sonucunda dokuma kumaşlarda doku tipinin aşınma ve boncuklanma dayanımı üzerinde önemli bir etkisi olduğu ortaya konulmuştur. Atlama sayısının az ve bağlantı sayısının fazla olduğu kumaşlarda aşınma ve boncuklanma dayanımlarının daha yüksek olduğu gözlenmiştir. Tekeoğlu ve Kavuşturan [10] akrilik, polyester, pamuk ve viskon olmak üzere dört farklı hammadde kullanılarak üretilen şenil ve makarna fantezi ipliklerin, bu ipliklerden dokunan kumaşların aşınma ve kopma mukavemetine etkilerini inceleyen deneysel bir çalışma sunmuşlardır.

\section{MATERYAL VE METOT}

\subsection{Materyal}

Çalışmada kullanılan kumaşlar; hammaddesi \%100 pamuklu, ipliği boyalı, farklı atkı ve çözgü sıklıklarında atkı ve çözgüde aynı numara ipliklerden kancalı dokuma makinesinde üretilmiş kumaşlardır. Farklı konstrüksiyonlardaki kumaşlara dokuma sonrası, yakma ve haşıl sökme ön terbiye işlemleri uygulanmıştır. Ön terbiye görmüş pamuklu kumaşların iplik numarası, sıklık, örgü türü ilgili standartlara göre kondüsyonlama sonrası tespit edilmiştir [11,12].
Deneysel çalışma kapsamında, kumaşlara yapılan örgü analizi ile bezayağı, 2/2 dimi ve panama olmak üzere, üç farklı örgü raporu olduğu tespit edilmiştir. Şekil 1.'de tespit edilen örgü raporları, Çizelge 1, 2 ve 3 'te ise örgü türlerine göre iplik numarası, atkı ve çözgü sıklığı ölçüm sonuçları verilmiştir (B:bezayağı, D:dimi P: panama).
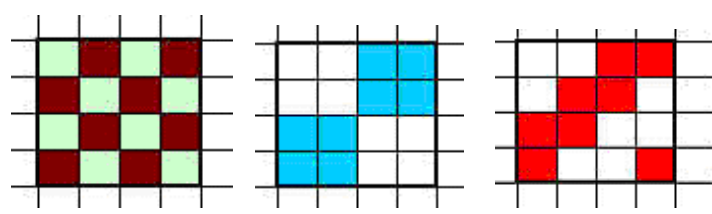

Bezayağ 1

Panama (2/2)

$\operatorname{Dimi}(2 / 2 \quad Z)$

Şekil 1. Kumaş numunelerinin örgü tipleri

Çizelge 1. Bezayağı örgüde kumaşların iplik numarası ve sıklık sonuçları [1]

\begin{tabular}{|c|c|c|c|}
\hline $\begin{array}{c}\text { Numune } \\
\text { no }\end{array}$ & $\begin{array}{c}\text { İplik } \\
\text { no } \\
(\mathrm{Ne})\end{array}$ & $\begin{array}{c}\text { Çözgü } \\
\text { sıklığı } \\
\text { (tel/cm) }\end{array}$ & $\begin{array}{c}\text { Atkı s1klığ } \\
(\mathrm{tel} / \mathrm{cm})\end{array}$ \\
\hline $1 \mathrm{~B}$ & \multirow{9}{*}{49,32} & 55,2 & 34,0 \\
\hline $2 B$ & & 55,8 & 30,0 \\
\hline $3 \mathrm{~B}$ & & 55,2 & 25,8 \\
\hline $4 B$ & & 47,8 & 33,8 \\
\hline $5 B$ & & 47,6 & 30,0 \\
\hline $6 \mathrm{~B}$ & & 48,0 & 25,8 \\
\hline $7 \mathrm{~B}$ & & 40,4 & 33,6 \\
\hline $8 \mathrm{~B}$ & & 40,6 & 30,6 \\
\hline 9B & & 40,6 & 26,6 \\
\hline $10 \mathrm{~B}$ & \multirow{6}{*}{39,67} & 44,8 & 27,0 \\
\hline 11B & & 44,8 & 24,8 \\
\hline 12B & & 44,6 & 20,6 \\
\hline 13B & & 39,8 & 27,2 \\
\hline 14B & & 39,8 & 23,6 \\
\hline 15B & & 40,0 & 20,0 \\
\hline $16 \mathrm{~B}$ & \multirow{9}{*}{29,95} & 38,4 & 31,0 \\
\hline 17B & & 38,4 & 26,0 \\
\hline 18B & & 37,6 & 20,0 \\
\hline 19B & & 34,0 & 29,8 \\
\hline $20 \mathrm{~B}$ & & 34,6 & 26,0 \\
\hline $21 \mathrm{~B}$ & & 33,8 & 20,0 \\
\hline 22B & & 29,2 & 29,8 \\
\hline 23B & & 28,4 & 25,6 \\
\hline $24 \mathrm{~B}$ & & 28,2 & 20,4 \\
\hline
\end{tabular}


Çizelge 2. Dimi örgüde kumaşların iplik numarası ve sıklık sonuçları [1]

\begin{tabular}{|c|c|c|c|}
\hline $\begin{array}{c}\text { Numune } \\
\text { no }\end{array}$ & $\begin{array}{c}\text { iplik } \\
\text { no } \\
(\mathrm{Ne})\end{array}$ & $\begin{array}{c}\text { Çözgü } \\
\text { sıklığ1 } \\
\text { (tel/cm) }\end{array}$ & $\begin{array}{l}\text { Atk1 sıklığ } \\
\text { (tel/cm) }\end{array}$ \\
\hline $1 \mathrm{D}$ & \multirow{9}{*}{49,32} & 55,8 & 33,8 \\
\hline $2 \mathrm{D}$ & & 55,8 & 29,8 \\
\hline $3 \mathrm{D}$ & & 55,0 & 25,8 \\
\hline $4 \mathrm{D}$ & & 48,2 & 33,4 \\
\hline $5 \mathrm{D}$ & & 48,0 & 29,6 \\
\hline $6 \mathrm{D}$ & & 47,4 & 25,6 \\
\hline $7 \mathrm{D}$ & & 40,6 & 34,6 \\
\hline $8 \mathrm{D}$ & & 40,8 & 30,6 \\
\hline 9D & & 40,4 & 26,4 \\
\hline 10D & \multirow{6}{*}{39,67} & 45,0 & 26,8 \\
\hline 11D & & 45,0 & 24,2 \\
\hline $12 \mathrm{D}$ & & 45,2 & 20,4 \\
\hline 13D & & 40,0 & 26,6 \\
\hline 14D & & 40,4 & 24,2 \\
\hline $15 \mathrm{D}$ & & 40,4 & 20,4 \\
\hline $16 \mathrm{D}$ & \multirow{9}{*}{29,95} & 38,6 & 31,0 \\
\hline 17D & & 38,4 & 26,0 \\
\hline 18D & & 38,4 & 21,0 \\
\hline 19D & & 34,8 & 31,0 \\
\hline $20 \mathrm{D}$ & & 34,8 & 25,4 \\
\hline $21 D$ & & 33,6 & 21,0 \\
\hline $22 \mathrm{D}$ & & 27,8 & 31,0 \\
\hline $23 \mathrm{D}$ & & 27,8 & 25,0 \\
\hline $24 \mathrm{D}$ & & 27,6 & 20,6 \\
\hline
\end{tabular}

\subsection{Metot}

\subsubsection{Boncuklanma Tayini (Martindale Pilling)}

\%100 pamuklu kumaşlara, TS EN ISO 12945-2 standardı [13] esas alınarak çalışma kapsamında, Martindale Pilling testi uygulanmıştır. Deney numunelerinin boncuklanma oluşumunu tayin etmeden önce, numune kumaşlara yıkamadan sonra boyut değişimi tayini yapılmıştır [14]. Test numuneleri, üç adedi deney parçası üç adedi de alt kumaş olarak $14 \mathrm{~cm}$ çapında toplam 6 adet hazırlanmıştır (standardın gerektirdiği numune sayıs1 3 çifttir). Boncuklanma testi, dairesel deney numunesinin alt kumaşla (deney numunesinin aynısından ve aynı ölçüde) sürtünmesi sağlanarak yürütülmektedir. Yüzey tüylenmesi ve boncuklanmanın subjektif olarak değerlendirilmesi, sürtme deneyinin bu aşamasından sonra yapılmaktadır. Boncuklanma testi, Martindale cihazının belirli devirlerinde gerçekleşmekte olup 125, 500, 1000 ve 2000 devirlerde cihaz durdurulmakta ve her devir sonunda üst deney parçalarına bakılarak tüylenme ve boncuklanma gözlenmektedir. Bu çalışmada kullanılan pamuklu kumaşlarda boncuklanma tayini, 2000 devre kadar uygulanmış olup boncuklanma cihazı Şekil 2'de verilmiştir [1]. Boncuklanmanın değerlendirilmesi, Şekil 3'te verilen pilliscope'ta yapılmaktadır. Pilliscope, kumaşların üzerinde oluşan boncuklanmanın 5 standart fotoğrafa göre açılı yerleştirilmiş halojen lambalarla karşılaştırılmasını sağlayan bir cihazdır. 2000 devre kadar uygulanan pilling testi sonunda, pilliscope kullanılarak dokuma kumaşların karşılaştırma fotograflarıyla değerlendirme yapılmaktadır [1].

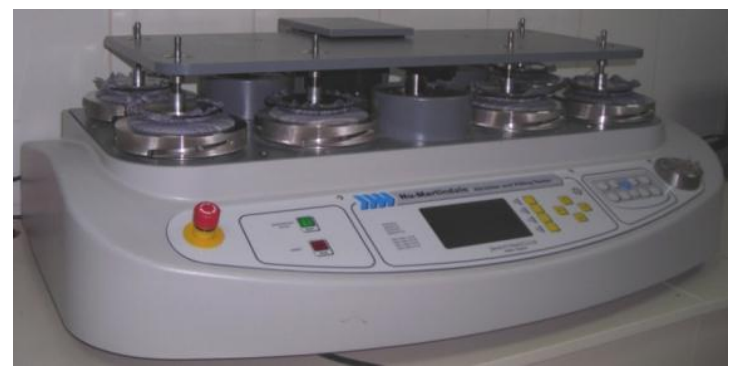

Şekil 2. Martindale aşındırma ve boncuklanma test cihazı

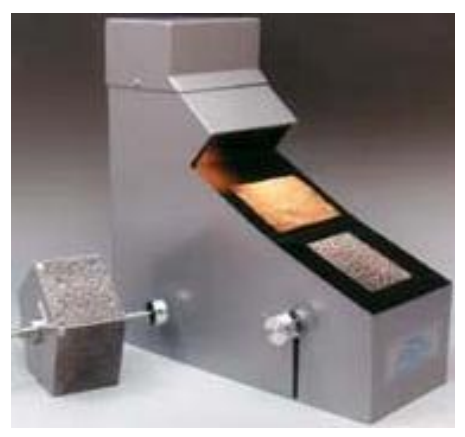

Şekil 3. Pilliscope boncuklanma tayin kabini [15] 
Çizelge 3. Panama örgüde kumaşların iplik numarası ve sıklık sonuçları [1]

\begin{tabular}{|c|c|c|c|}
\hline & $\begin{array}{c}\text { iplik } \\
\text { no } \\
\text { (Ne) }\end{array}$ & $\begin{array}{c}\text { Çözgü } \\
\text { sıklığı } \\
\text { (tel/cm) }\end{array}$ & $\begin{array}{c}\text { Atkı sıklığı } \\
\text { (tel/cm) }\end{array}$ \\
\hline $1 \mathrm{P}$ & \multirow{9}{*}{49,32} & 55,6 & 34,0 \\
\hline $2 \mathrm{P}$ & & 56,2 & 30,0 \\
\hline $3 \mathrm{P}$ & & 56,0 & 26,0 \\
\hline $4 \mathrm{P}$ & & 48,2 & 33,6 \\
\hline $5 \mathrm{P}$ & & 48,0 & 30,4 \\
\hline $6 \mathrm{P}$ & & 48,0 & 25,8 \\
\hline $7 \mathrm{P}$ & & 40,6 & 34,0 \\
\hline $8 \mathrm{P}$ & & 39,6 & 31,0 \\
\hline $9 \mathrm{P}$ & & 39,6 & 26,6 \\
\hline $10 \mathrm{P}$ & \multirow{6}{*}{39,67} & 45,0 & 26,6 \\
\hline $11 \mathrm{P}$ & & 45,2 & 24,2 \\
\hline $12 \mathrm{P}$ & & 45,2 & 20,4 \\
\hline $13 \mathrm{P}$ & & 40,0 & 26,4 \\
\hline $14 \mathrm{P}$ & & 40,0 & 24,0 \\
\hline $15 \mathrm{P}$ & & 40,0 & 20,0 \\
\hline $16 \mathrm{P}$ & \multirow{9}{*}{29,95} & 38,4 & 30,0 \\
\hline $17 \mathrm{P}$ & & 38,2 & 26,0 \\
\hline $18 \mathrm{P}$ & & 37,6 & 21,0 \\
\hline 19P & & 33,8 & 30,0 \\
\hline $20 \mathrm{P}$ & & 34,2 & 25,4 \\
\hline $21 \mathrm{P}$ & & 33,4 & 20,0 \\
\hline $22 \mathrm{P}$ & & 27,8 & 30,6 \\
\hline $23 \mathrm{P}$ & & 27,8 & 25,4 \\
\hline $24 \mathrm{P}$ & & 27,2 & 20,0 \\
\hline
\end{tabular}

Boncuklanma değerlendirmesi 1-5 aralığında değişen, ara değerleri de bulunan standart skala referans alınarak yapılmaktadır $(1,1-2,2,2-3,3$,
3-4, 4, 4-5, 5). Bu skalada 1 en kötü, 5 ise en iyi olarak tanımlanmaktadır (Çizelge 4).

Çizelge 4. Boncuklanma değerlendirme skalası

\begin{tabular}{|c|l|}
\hline Derece & \multicolumn{1}{|c|}{ Tanımı } \\
\hline 5 & Değişme yok \\
\hline 4 & $\begin{array}{l}\text { Hafif bir tüylenme ve/veya kısmen } \\
\text { oluşmuş boncuklanma }\end{array}$ \\
\hline 3 & $\begin{array}{l}\text { Orta düzeyde tüylenme ve/veya orta } \\
\text { düzeyde boncuklanma }\end{array}$ \\
\hline 2 & $\begin{array}{l}\text { Belirgin bir tüylenme ve/veya belirgin } \\
\text { boncuklanma }\end{array}$ \\
\hline 1 & $\begin{array}{l}\text { Yoğun yüzey tüylenmesi ve/veya etkin } \\
\text { boncuklanma }\end{array}$ \\
\hline
\end{tabular}

\subsubsection{Aşınma ile Kütle Kaybı Tayini (Martindale Aşınma ile Kütle Kaybı)}

BS 5690 standardı [16] esas alınarak çalışmada kullanılan \%100 pamuklu kumaşlara aşınma dayanımı (kütle kaybı) tayini yapılmıştır. Deney parçaları olarak; numuneler ve destek köpüğü kesici numune şablonu kullanılarak $3,8 \mathrm{~cm}$ çapında, keçe ve standart yün kumaş $14 \mathrm{~cm}$ çapında hazırlanmaktadır. Aşındırmada test numunesinin çalışma basıncı $9 \mathrm{kPa}$ olup, numunelerin aşınma dayanımının test edildiği cihaz, Şekil 2'de verilen Martindale cihazıdır. Bu cihaz, boncuklanma tayini için de kullanıldığından, cihaz eğer boncuklanma test pozisyonunda ise, aşındırma test pozisyonuna getirilmelidir. $3.8 \mathrm{~cm}$ çapında hazırlanan deney numunesi ve destek köpüğü, cihazın ön tarafinda bulunan numune hazırlama bölümünde üst üste konularak numune tutucu gövdesine yerleştirilir. $14 \mathrm{~cm}$ çapındaki yün kumaş ile keçe, önce keçe üzerine aşındırıcı yün kumaş olarak yerleştirilip, bask1 ağırlığ1 kullanılarak cihazın alt tablasına sabitlenir. Böylece alt tablada aşındırıcı yün kumaş üst tablada deney numunesi olmak üzere numune seti hazırlanmış olur. Belirlenen tur sayısına göre cihaz çalıştırılıp, tur bitiminde deney numunelerinin ağırlık kaybı belirlenerek \% kütle kaybı, $\mathrm{m}_{1}$ test öncesi numune ağırlığı (gram), $\mathrm{m}_{2}$ test sonrası numune ağırlığı (gram) olmak üzere eşitlik (1) ile tespit edilir [1].

Kütle kaybı $(\%)=\left(m_{1}-m_{2}\right) / m_{1}$ 


\section{ARAŞTIRMA BULGULARI VE TARTIŞMA}

\subsection{Boncuklanma Değerlendirmesi}

$\% 100$ pamuklu ipliği boyalı kumaşlara, ilgili standart esas alınarak Martindale Piling testi uygulanması neticesinde elde edilen boncuklanma değerlendirmesi Çizelge 5'te verilmiştir. Çizelge 1'de verilen boncuklanma değerlendirme skalasında, her bir değerlendirmenin tanımı verilmiştir.
Boncuklanma tayininde elde edilen Çizelge 5'te yer alan boncuklanma ortalama dereceleri Şekil 4'te verilmiştir. Çizelge 5 ve Şekil 4'ten görüldüğü üzere bağlantı noktası fazla olan bezayağ1 dokuda, numunelerin boncuklanma eğiliminin daha az olduğu tespit edilmiştir. Dimi $(2 / 2)$ ve panama dokularda bağlantı noktası daha az olup, yan yana gelen ipliklerin teması nedeniyle boncuklanma oluşumuna sebep olan lif dolaşması daha fazla olmuş, dolayısıyla da boncuklanma değerleri, bezayağından daha kötü çıkmıştır. Çizelge 5'teki 2-3 değeri 2,5 olarak 3-4 değeri ise 3,5 olarak Şekil 4'de yer almıştır.

Çizelge 5. Deneysel çalışmada kullanılan tüm kumaşların boncuklanma sonuçları [1]

\begin{tabular}{|c|c|c|c|c|c|}
\hline Numune no & $\begin{array}{c}\text { Boncuklanma } \\
\text { değeri }\end{array}$ & $\begin{array}{c}\text { Numune } \\
\text { no }\end{array}$ & $\begin{array}{c}\text { Boncuklanma } \\
\text { değeri }\end{array}$ & $\begin{array}{c}\text { Numune } \\
\text { no }\end{array}$ & $\begin{array}{c}\text { Boncuklanma } \\
\text { değeri }\end{array}$ \\
\hline $1 \mathrm{~B}$ & 2 & 1D & 2 & $1 \mathrm{P}$ & 2 \\
\hline $2 \mathrm{~B}$ & $2-3$ & $2 \mathrm{D}$ & 2 & $2 \mathrm{P}$ & $2-3$ \\
\hline $3 \mathrm{~B}$ & $3-4$ & $3 \mathrm{D}$ & 2 & $3 \mathrm{P}$ & 2 \\
\hline $4 B$ & $3-4$ & $4 \mathrm{D}$ & 3 & $4 \mathrm{P}$ & 3 \\
\hline $5 B$ & $3-4$ & $5 \mathrm{D}$ & $2-3$ & $5 \mathrm{P}$ & $2-3$ \\
\hline $6 \mathrm{~B}$ & $3-4$ & $6 \mathrm{D}$ & 2 & $6 \mathrm{P}$ & $2-3$ \\
\hline $7 \mathrm{~B}$ & $3-4$ & $7 \mathrm{D}$ & 3 & $7 \mathrm{P}$ & 3 \\
\hline $8 B$ & 3 & $8 \mathrm{D}$ & $2-3$ & $8 \mathrm{P}$ & $2-3$ \\
\hline $9 \mathrm{~B}$ & 3 & 9D & $2-3$ & 9P & $2-3$ \\
\hline 10B & $3-4$ & 10D & $1-2$ & $10 \mathrm{P}$ & 2 \\
\hline 11B & $2-3$ & $11 \mathrm{D}$ & $1-2$ & $11 \mathrm{P}$ & 2 \\
\hline 12B & $2-3$ & $12 \mathrm{D}$ & $1-2$ & $12 \mathrm{P}$ & 2 \\
\hline $13 \mathrm{~B}$ & 2 & $13 \mathrm{D}$ & $1-2$ & $13 \mathrm{P}$ & 2 \\
\hline 14B & $2-3$ & $14 \mathrm{D}$ & $1-2$ & $14 \mathrm{P}$ & 2 \\
\hline $15 \mathrm{~B}$ & 2 & $15 \mathrm{D}$ & $1-2$ & $15 \mathrm{P}$ & 2 \\
\hline $16 \mathrm{~B}$ & $3-4$ & $16 \mathrm{D}$ & $2-3$ & $16 \mathrm{P}$ & $2-3$ \\
\hline 17B & 3 & $17 \mathrm{D}$ & 2 & $17 \mathrm{P}$ & 3 \\
\hline 18B & 3 & $18 \mathrm{D}$ & 2 & $18 \mathrm{P}$ & 2 \\
\hline 19B & $3-4$ & 19D & 3 & $19 \mathrm{P}$ & 3 \\
\hline $20 \mathrm{~B}$ & $3-4$ & $20 \mathrm{D}$ & 3 & $20 \mathrm{P}$ & 3 \\
\hline $21 \mathrm{~B}$ & $3-4$ & 21D & 2 & $21 \mathrm{P}$ & $2-3$ \\
\hline 22B & $3-4$ & $22 \mathrm{D}$ & $2-3$ & $22 \mathrm{P}$ & $2-3$ \\
\hline 23B & $3-4$ & $23 \mathrm{D}$ & 3 & $23 \mathrm{P}$ & $2-3$ \\
\hline $24 \mathrm{~B}$ & 3 & $24 \mathrm{D}$ & 2 & $24 \mathrm{P}$ & $2-3$ \\
\hline
\end{tabular}




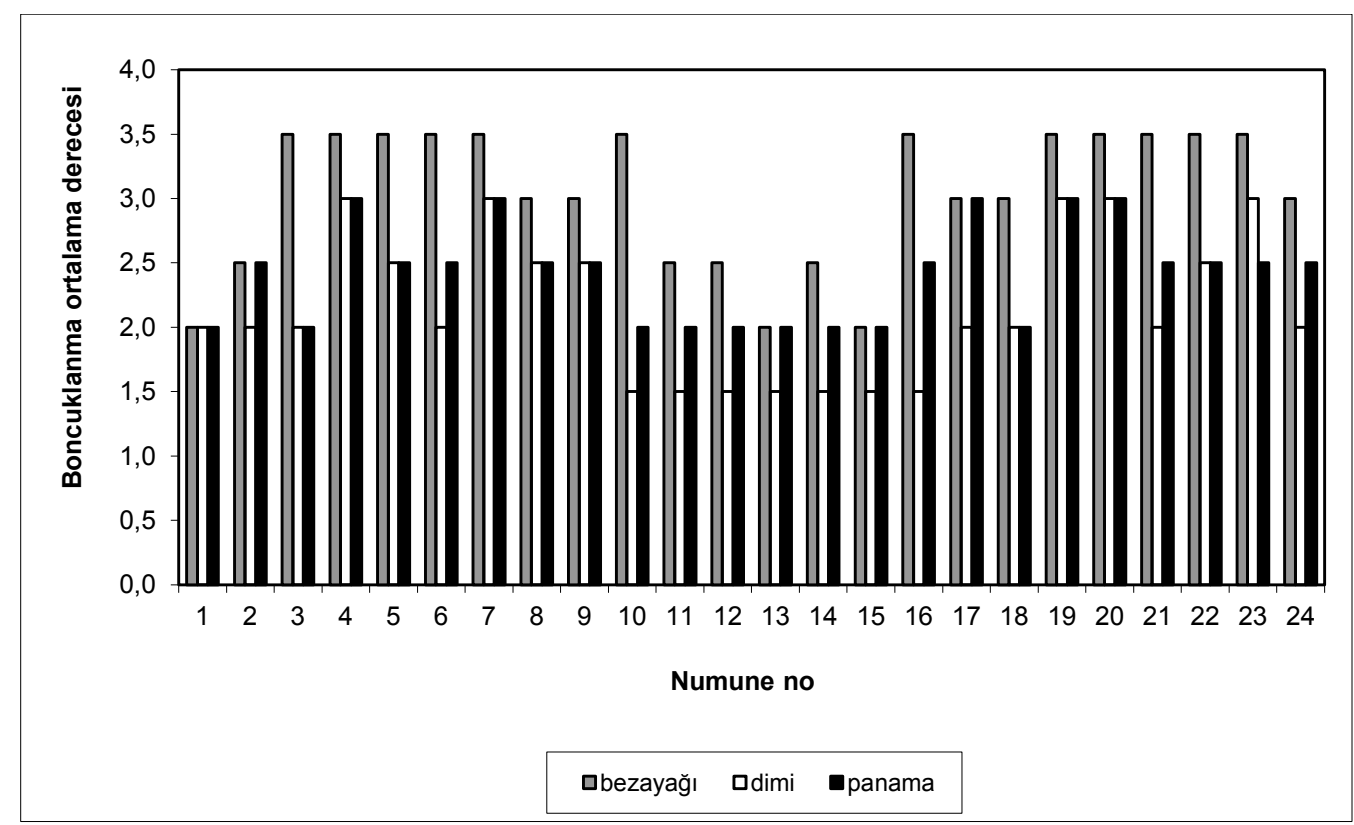

Şekil 4. Numunelerin boncuklanma ortalama dereceleri [1]

Çalışmada teste tabi tutulan kumaşlar, tek kat iplikten dokunmuştur. Katlı ipliklerde, katlı iplik oluşum aşamasında verilen ikinci büküm, yüzeye çıkmış bazı lifleri iplik içine tekrar hapsettiği için, bu tür kumaşlarda boncuklanma eğiliminin tek kat iplikten dokunan kumaşlardaki boncuklanma eğiliminden daha az olabileceği düşünülmektedir. Boncuklanma daha çok, terbiye işlemi görmüş (mamul) kumaşlara uygulanan bir analiz olup, lif türü, iplik özellikleri, iplik eğirme yöntemi, kumaş özellikleri (örgü türü gibi), kumaşın gördüğü terbiye işlemleri (ön terbiye, boyama, apre gibi) olarak bir çok faktörden etkilenebilen bir performans özelliğidir.

\subsection{Aşınma ile Kütle Kaybı Değişimi}

BS 5690'a göre, çalışmada kullanılan tüm kumaşlara uygulanan Martindale aşınma dayanımında elde edilen kütle kaybı (\%) ortalama sonuçları Çizelge 6'da verilmiştir.

Aşındırıcı kumaş etkisiyle numunelerdeki kütle kaybı (\%) çizelgeden görüldüğü üzere dimi ve panama örgü yapılarında daha fazladır. Panamada enine ve boyuna yönde grup halinde hareket eden çözgü ve atkı sayısı birbirine eşit olduğundan gevşek ve gözenekli bir doku meydana getirirler ve dayanıklılığı düşük bir kumaş yapısı oluştururlar, böylece aşınmaya karşı dayanıksızlık sergilerler [1].

Aşındırıcı kumaş etkisiyle numunelerdeki kütle kayb1 (\%) değişimi, tüm kumaşlar için Şekil 5'te bir grafikle gösterilmiştir. Burada en fazla kütle kaybının olduğu örgü türünün panama ve dimi örgüdeki kumaşlar olduğu ve en az kütle kaybının da bezayağı kumaşlarda olduğu görülmektedir. Bezayağı yapıda, bağlantı şeklinden dolayı örgünün daha sıkı olması ve ipliklerin birbirinden kolay ayrılmaması nedeniyle, aşınma ile kütle kaybının, diğer örgülere göre daha az olmasını sağlamıştır [1].

\section{SONUÇ}

$\mathrm{Bu}$ çalışmada, \%100 pamuklu hammaddeden, farklı sıklıklardaki atkı ve çözgü ipliklerinden farklı örgülerde dokunmuş kumaşların iplik 


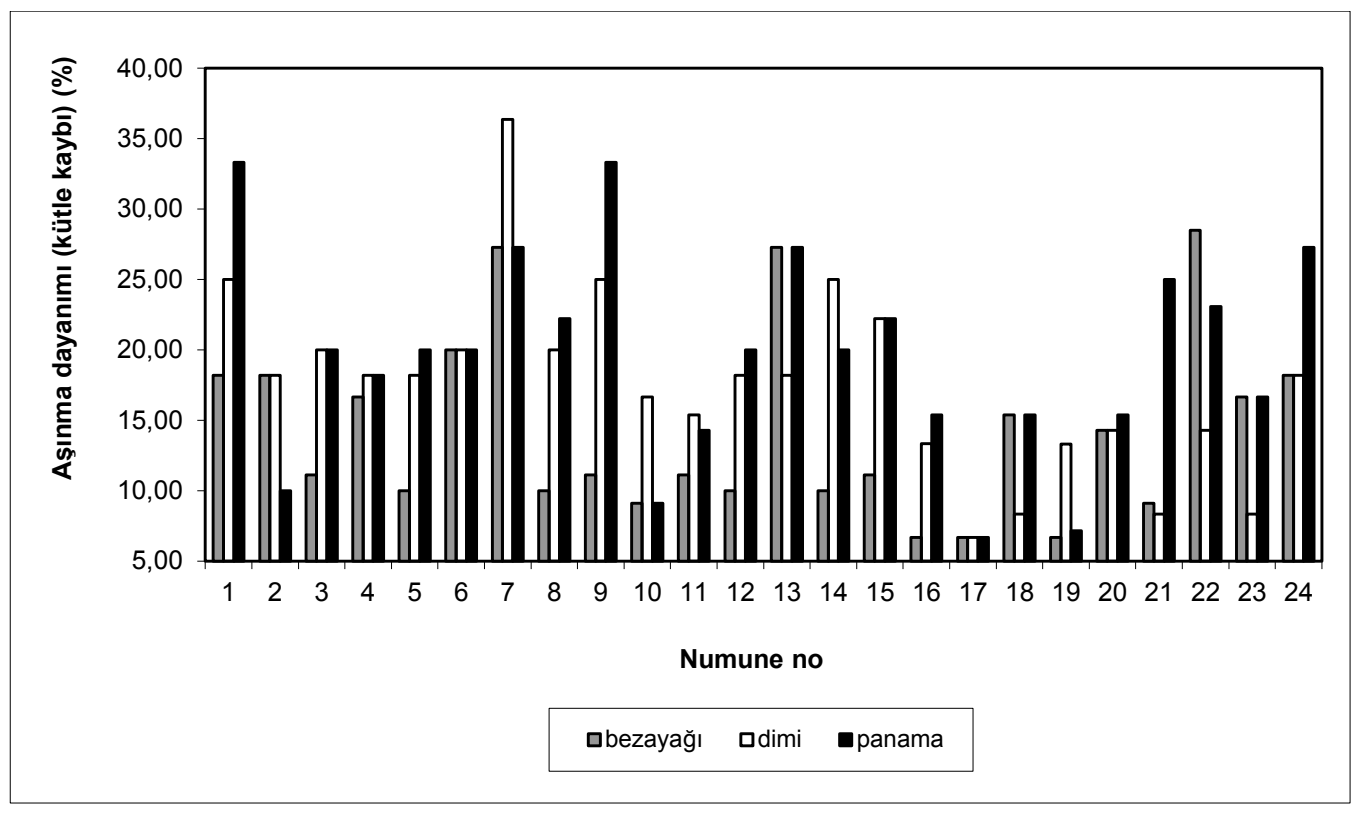

Şekil 5. Numunelerin aşınma ile kütle kaybı (\%) [1]

numarası, atkı ve çözgü sıklıkları, örgü türü gibi fiziksel özellikleri ile boncuklanma ve aşınma ile kütle kaybı performans özellikleri ilgili standartlara göre tespit edilmiştir. Elde edilen sonuçlar değerlendirilerek farklı kumaş konstrüksiyonlarının boncuklanmaya ve aşınma ile kütle kaybına etkisi yorumlanmıştır.

Çalışmada uygulanan boncuklanma tayini sonucunda mevcut üç örgü türü için birlikte değerlendirme yapıldığında, bağlantı noktası fazla olan bezayağı dokuda, numunelerin boncuklanma eğiliminin daha az olduğu tespit edilmiştir. Dimi $(2 / 2)$ ve panama dokularda bağlantı noktası daha az olup, yan yana gelen ipliklerin teması nedeniyle boncuklanma oluşumuna sebep olan lif dolaşması daha fazla olmuş, dolayısıyla da boncuklanma değerleri, bezayağından daha kötü çıkmıştır.

Aşındırıcı kumaş etkisiyle numunelerdeki kütle kaybı değerlendirildiğinde genel olarak dimi ve panama örgü yapılarında kütle kaybının daha fazla olduğu görülmüştür. Burada numune kumaşlarda en az kütle kayb1, örgü türü olarak genel değerlendirmede bezayağı örgüdür. Bezayağ yapıda, bağlantı şeklinden dolayı örgünün daha sıkı olması ve ipliklerin birbirinden kolay ayrılmaması nedeniyle, aşınma sonunda kütle kaybının diğer örgülere göre daha az olmasını sağlamıştır.

Boncuklanma ve aşınma testleri genellikle terbiye işlemi görmüş (mamul) kumaşlara uygulanan analizler olup, lif türü, iplik özellikleri, iplik eğirme yöntemi, kumaş özellikleri (örgü türü gibi), kumaşın gördüğü terbiye işlemleri (ön terbiye, boyama, apre gibi) olarak bir çok faktörden etkilenebilen performans özellikleridir.

\section{KAYNAKLAR}

1. Doba Kadem, F., 2007. İpliği Boyalı Pamuklu Kumaşlarda Bazı Fiziksel Özelliklerin Seçilmiş Performans Özellikleriyle İlişkisinin Araştırılması, Doktora Tezi, Çukurova Üniversitesi, Fen Bilimleri Enstitüsü, Tekstil Mühendisliği Anabilim Dalı, s.219, Adana,

2. Mohamed, M.H, Lord, P.R., 1973. Comparison of Physical Properties of Fabrics Woven from Open-End and Ring Spun Yarns, Textile Research Journal, 
Vol.43 No:3, 154-166.

3. Ukponmwan, J.O., 1988. Assessment of Fabric Wear and Handle Caused by Increments of Accelator Abrasion in Dry Conditions Part I: Changes in Some Fabric Mechanical Properties as a Result of Abrasion', Journal of the Textile Institute, Vol:79, No:4, 568-579.

4. Ukponmwan, J.O., 1993. Effect of Wet Abrasive Wear on the Tensile Properties of Cotton and Polyester-Cotton Fabrics, Journal of Testing\&Evaluation, Vol:21, No:1, 84-93.

5. Efimova, O.G., Kotomina R.I., Saakyan N.V., Skurıkhına E.E., 2003. Investigating a Device for the Abrasion Testing of Fabrics of Different Fibrous Compositions Izvestiya Vysshikh Uchebnykh Zavedenii, No:3, 2930.

6. Can, Y., 2004. İplik Özelliklerinin Pamuklu Bezayağı Kumaşların Bazı Mekanik Özelliklerine Etkileri Üzerine Bir Araştırma'. Doktora Tezi, Ege Üniversitesi, Fen Bilimleri Enstitüsü, Tekstil Mühendisliği Anabilim Dalı, s.160, İzmir.

7. Lam, J.K.C., Postle, R., 2006. Multivariate Studies of Mechanical Properties for Wool and Cotton Fabrics, Textile Research Journal, Vol:76, No:5, 414-425.

8. Taşkın C., Özgüney, A.T., Gürkan, P., Özcelik, G., 2006. Kompakt ve Konvansiyonel Ring İpliklerinden Dokunmuş Pamuklu Kumaşların Farklı Terbiye İşlemleri Sonrası Boncuklanma Özelliklerinin Karşılaştırılması, Yıl: 16, Sayı 2, 123-127.

9. Kaynak, H.K., Topalbekiroğlu M., 2007. Dokuma Kumaşlarda Doku Tipinin Aşınma ve Boncuklanma Dayanımı Üzerine Etkilerinin Araştırılması, Tekstil ve Konfeksiyon, y1l:17, Say1 1, 40-44.

10. Tekeoğlu, O., Kavuşturan, Y., 2011. Şenil ve Makarna Döşemelik Kumaşların Aşınma Dayanımı ve Kopma Mukavemeti, Tekstil ve Konfeksiyon, yıl:21, Say1 4, 336-342.

11. TS 240 EN 20139, 1995. TekstilKondüsyonlama ve Deneyler için Standart Atmosfer Şartları. Türk Standartları Enstitüsü, Ankara.
12. TS 250 EN 1049-2, 1996. TekstilDokunmuş Kumaşlar Yapı Analiz MetodlarıKısım 2- Birim Uzunluktaki İplik Sayısının Tayini. Türk Standartları Enstitüsü, Ankara.

13. TS EN ISO 12945-2, 2002. TekstilKumaşlarda Yüzey Tüylenmesi ve Boncuklanma Yatkınlığının Tayini-Bölüm 2: Geliştirilmiş Martindale Metodu, Türk Standartları Enstitüsü, Ankara.

14. BS EN ISO 6330, 2001. Textile Domestic Washing and Drying Procedures for Textile Testing.

15. http://www.sdlatlas.com/results? search=pilis cope, erişim tarihi: Mart 2013

16. BS 5690, 1991. Method for Determination of Abrasion Resistance of Fabrics, Misis Apre (Adana) Mamul Kalite Kontrol Laboratuarı Deney Föyü. 
